\title{
Symptom Reporting and Associations With Compensation Status, Self-Awareness, Causal Attributions, and Emotional Wellbeing Following Traumatic Brain Injury
}

\author{
Tamara Ownsworth \\ The University of Queensland, Australia \\ Jennifer M. Fleming \\ The University of Queensland, Australia and Occupational Therapy Department, Princess Alexandra \\ Hospital, Brisbane, Australia
}

Sascha Hardwick

The University of Queensland, Australia

\begin{abstract}
Individuals seeking compensation following traumatic brain injury (TBI) are often found to report a disproportionately high level of symptoms relative to objective indicators of impairment. Previous studies highlight that level of symptom reporting is also related to self-awareness, causal attribution, and emotional wellbeing. Therefore, the reasons for high symptom reporting in the context of compensation are generally unclear. This study aimed to identify whether self-awareness, causal attribution, and emotional wellbeing are significantly associated with level of symptom reporting after controlling for compensation status. A sample of 54 participants with TBI comprised two groups, namely, claimants $(n=27)$ and non-claimants $(n=27)$, who were similar in terms of demographic and neuro-cognitive variables. Participants completed the Symptom Expectancy Checklist, Hospital Anxiety Depression Scale, Awareness Questionnaire and a causal attribution scale. A series of independent $t$ tests and Pearson's correlations identified that a higher level of symptom reporting was associated with the following: seeking compensation, less severe TBI, increased age, greater self-awareness, increased post-injury changes reported by relatives, a higher level of mood symptoms, and a tendency to blame other people. Multivariate analysis identified that after controlling for demographic, injury, and compensation status variables, level of mood symptoms and self-awareness were significantly associated with level of symptom reporting. The findings suggest that mood symptoms and heightened self-awareness are significantly related to high symptom reporting independent of compensation status, thus supporting the need for clinicians to interpret symptom reporting within a biopsychosocial context.
\end{abstract}

Individuals seeking compensation following traumatic brain injury (TBI) often report more symptoms than non-claimants (Gasquoine, 1997b; McKinlay, Brooks, \& Bond, 1983; Paniak et al.,
2002) and the level of reported symptomatology may increase over time (Cartlidge, 1978). A common explanation for excessive symptom reporting is that individuals misrepresent their 
symptoms for secondary gains such as attention from healthcare professionals or financial benefits (Binder \& Rohling, 1996; Karzmark, Hall, \& Englander, 1995). However, alternative explanations for individuals' preoccupation with their post-injury complaints relate to the experience of seeking compensation itself, which may be associated with attributions of external causality, heightened self-awareness, and emotional distress (Kreutzer, Harris-Marwitz, \& Myers, 1990; McKinlay et al., 1983). Furthermore, some individuals with TBI who are not involved in the compensation process report a disproportionately high level of symptoms relative to more objective indices of impairment (Cicerone, 1991). The following review examines various issues related to symptom reporting with particular emphasis on the influence of compensation seeking, self-awareness, causal attributions, and emotional wellbeing, which form the basis of the present study.

The main methods for examining individuals' perceptions of their impairments following TBI include open or closed interview questions, questionnaire ratings of symptom frequency and severity (Trahan, Ross, \& Trahan, 2001), or symptom endorsement (i.e., yes/no responses). The latter method can be particularly useful for identifying the degree to which individuals overreport common symptoms, or physical, cognitive, and behavioural impairments arising from TBI, relative to base rates for normal controls (Mittenberg, DiGiulio, Perrin, \& Bass, 1992). Eliciting individuals' perceptions of their symptomatology during assessment can provide important insight into their beliefs and coping style and inform the development of treatment interventions (Cicerone, 1991).

Predictors of symptom reporting have been investigated extensively for individuals with TBI irrespective of their compensation status. Overall, no consistent differences in level of symptom reporting have emerged from the literature with respect to age, gender, education, race, chronicity, or pre-injury psychological adjustment (Gasquoine, 1997b; Karzmark et al., 1995; Mittenberg et al., 1992; Trahan et al., 2001). Research investigating severity of injury has generally failed to support the hypothesis that individuals with more severe brain injuries report a greater degree of symptoms (Karzmark et al., 1995; Mittenberg et al., 1992). Moreover, in some studies individuals with mild TBI reported a greater degree of symptoms than individuals with severe TBI (Sawchyn, Mateer, \& Suffield, 2005; Youngjohn, Burrows, \& Erdal, 1995). This finding has been attributed to individuals with severe injuries underreporting their symptoms due to reduced self-awareness (Cicerone,
1991; Gasquoine, 1997a, 1997b). However, an alternative explanation is that individuals with mild TBI are more likely to report a higher level of symptoms, particularly in the context of a compensation claim (Binder \& Rohling, 1996). To date, studies examining level of symptom reporting according to compensation status and severity of injury have not investigated self-awareness (McKinlay et al., 1983; Trahan et al., 2001).

In general, previous neuropsychological studies indicate that individuals' level of symptom reporting is unrelated to their degree of cognitive impairment (Allen \& Ruff, 1990; Cicerone, 1991; Mittenberg et al., 1992). However, research has found that underreporting of symptoms, as compared with significant others' ratings of impairment, is associated with poorer performance on measures of executive functioning (Bogod, Mateer, \& McDonald, 2003; Burgess, Alderman, Evans, Emslie, \& Wilson, 1998; Ownsworth, McFarland, \& Young, 2002). Therefore, individuals' subjective accounts of disability are not typically associated with more objective indices of impairment; hence there is a need to understand the role of nonneurological factors.

It has been argued that while symptoms may initially have a neurological basis following mild TBI, their persistence can be maintained to some extent by sociocultural and psychological factors (Karzmark et al., 1995; Mittenberg et al., 1992). Similarly, the degree of symptoms experienced by individuals with moderate or severe TBI may be exacerbated by these factors (Kreutzer et al., 1990; Williams, 1997). With this in mind, theoretical perspectives on illness behaviour may assist in understanding high symptom reporting following TBI. Kirmayer and Taillefer (1997) presented a multifactorial model in which individuals' experience with illness was viewed in a biopsychosocial context. The model proposes that the events of illness, emotional distress, and everyday physiological variations each produce sensations that increase attention to the body. Some individuals attribute these sensations to symptoms of serious disease or disorder, which generates worry and catastrophic beliefs. Their experience in this role is shaped by the sociocultural context, which may reinforce an individual's reaction to symptoms (see also Brown, 2004). Contextual factors (e.g., family reactions, healthcare providers, and the insurance or compensation system) and dispositional factors (e.g., personality, attentional set, and coping behaviour) were proposed to moderate this process (Kirmayer \& Taillefer, 1997). 
In the context of TBI, this multifactorial model suggests that, in addition to neuro-cognitive factors, various sociocultural and psychological factors may contribute to high symptom reporting. In particular, the role of financial incentives in maintaining symptoms and disability following TBI has been well recognised. Various studies highlight the questionable validity of self-reports and reduced effort in neuropsychological testing for people seeking compensation (see Binder \& Rohling, 1996; Gasquoine, 1997b; Mittenberg, Patton, Canyock, \& Condit, 2002). However, previous studies have identified that high symptom reporting may also be related to heightened self-awareness, causal attribution, and emotional distress.

Research suggests that individuals with greater awareness of their deficits report more symptoms following brain injury (Ownsworth et al., 2002; Sawchyn et al., 2005). Thus, it is possible that individuals who report a high level of symptoms do so because they are more aware of their post-injury changes, while those reporting fewer symptoms are underreporting their problems (Cicerone, 1991). It could also be argued that individuals seeking compensation are more likely to develop heightened levels of awareness due to their experience with the compensation process (e.g., attending multiple assessments, interactions with lawyers, and keeping records of their symptoms; Kreutzer et al., 1990). However, research is yet to compare level of self-awareness between claimants and non-claimants.

Studies investigating attribution of causality have found that individuals with or without TBI who blame other people for a traumatic event are more likely to develop mood disorders than individuals who blame themselves (Williams, Williams, \& Ghadiali, 1998). Williams, Evans, Needham, and Wilson (2002) examined the association between level of posttraumatic stress symptoms following TBI and neuro-cognitive, self-awareness, and causal attribution variables. Causal attribution was measured on a rating scale from -5 (my own fault), to 0 (no-one's fault), to +5 (somebody else's fault). The findings indicated that a higher level of posttraumatic stress symptoms was associated with greater self-awareness and the tendency to blame other people (i.e., an external causal attribution). Level of posttraumatic stress was not significantly correlated with neurological, cognitive, or demographic variables. Despite emphasising the association between mood symptoms, self-awareness, and causal attribution, the study by Williams et al. (2002) did not investigate compensation status and, thus, the potentially inter- active influence of these variables upon symptom reporting is unclear.

It is well recognised that individuals with TBI who are more emotionally distressed report a higher level of symptoms than individuals with TBI who are less distressed (Godfrey, Partridge, Knight, \& Bishara, 1993; Jorge, Robinson, \& Arndt, 1993). Furthermore, individuals experiencing depression with or without TBI report more symptoms than individuals with TBI who do not experience depression (Suhr \& Gunstad, 2002; Trahan et al., 2001). Trahan et al. (2001) argued that while TBI and clinical depression may produce similar symptoms, this could not explain why individuals with depression who have no history of TBI reported more symptoms than individuals with TBI. Consistent with the model by Kirmayer and Taillefer (1997), researchers have suggested that individuals in emotional distress are preoccupied with their symptoms and overgeneralise the effects of their injury (Ownsworth \& Oei, 1998; Trahan et al., 2001). Thus, previous research suggests that level of symptom reporting is more related to emotional wellbeing or mood symptoms than brain injury and that people's beliefs and attributions about their injury play a critical role. However, it is yet to be determined whether level of symptom reporting is more related to compensation status or emotional wellbeing for individuals with TBI.

Therefore, the first aim of the present study was to compare levels of symptom reporting, selfawareness, causal attribution, and emotional wellbeing between claimants and non-claimants. The second aim was to examine, in an exploratory analysis, whether self-awareness, causal attribution, and mood symptoms are significantly associated with level of symptom reporting after controlling for compensation status. Unlike the majority of previous studies that have investigated symptom reporting in the context of compensation, the present study included both claimants and nonclaimants with TBI who were similar in terms of demographic characteristics, injury variables, and cognitive functioning. A between-group comparison of degree of cognitive impairment was based upon tests of executive function due to the finding that symptom underreporting is associated with executive impairment (Ownsworth et al., 2002). Consistent with previous research, it was hypothesised that claimants would report a higher level of symptoms than non-claimants. However, it was also hypothesised that after controlling for compensation status, level of symptom reporting would be significantly associated with level of self-awareness, causal attribution, and mood symptoms. 


\section{Methodology}

\section{Participants}

A convenience sample of 54 participants with TBI was recruited from two metropolitan-based outpatient brain injury rehabilitation units and two vocational rehabilitation services for people with acquired brain injury. Prior to recruitment, ethical clearance was obtained from the relevant ethics committee of a university and each rehabilitation centre. Eligibility for the study was determined in a screening assessment conducted by a treating professional. Individuals were deemed eligible for the study if they had no history of a pre-injury neurological event, psychiatric condition, or substance abuse disorder; were aged 16 to 65 years; and possessed adequate communication skills to complete the tests and questionnaires. Additionally, individuals were excluded if their claim had settled (i.e., were previous claimants). Based upon these criteria, six individuals were excluded and one individual eligible for the study declined. The sample comprised 42 males and 12 females who were aged between 18 and 57 years $(M=33.8, S D=11.5)$. Time since injury for the sample ranged from 0.5 to 9 years $(M=3.4, S D=$ 2.9; Note: three individuals were still involved in a compensation claim at 8 to 9 years' post-injury). Cause of injury included motor vehicle accidents $(n=31)$, motorbike accidents $(n=5)$, falls $(n=8)$, assaults $(n=3)$, horse-riding accidents $(n=2)$, and home or work-related accidents $(n=5)$. Duration of posttraumatic amnesia recorded in medical records ranged from 1 hour to 108 days $(M=38.4, S D=46.2)$ and Glasgow Coma Scale scores varied between 3 and $14(M=7.3, S D=$ 4.3). For the purpose of data analysis, severity of injury was coded into 'mild to moderate' $(n=17)$ and 'severe' ( $n=37)$ according to guidelines by Kolb and Whishaw (1996).

By chance, there were an equal number of individuals in the claimant $(n=27)$ and nonclaimant groups $(n=27)$. The existing formation of these groups can be understood in the context of the Australian legal system. Although nonclaimants had sustained an injury from a similar event (e.g., a traffic accident or a fall) to claimants, they were either not legally entitled to statutory compensation (e.g., workers compensation) or did not have a basis for a claim under common law (e.g., negligence). The type of personal injury claims included motor vehicle accident compensation under a fault-based system ( $n$ $=18)$, workers compensation $(n=3)$, public liability compensation $(n=4)$, and victims of crime compensation $(n=2)$.

\section{Measures}

Symptom reporting. Level of symptom reporting was assessed using the Symptom Expectancy Checklist (SEC; Mittenberg et al., 1992), which is a measure of symptom endorsement. The SEC measures symptom reporting by asking the respondent to respond 'yes' or 'no' to 30 items on a checklist (e.g., 'irritability', 'headache', and 'forgets appointment dates'), which is introduced by the following statement: 'Head injuries are a fact of life and can happen to anyone. We are interested in how your head injury has (or has not) affected your ability to do everyday things' (Mittenberg et al., 1992, p. 201). Scores range between 0 and 30 (maximum endorsement). Mittenberg et al. (1992) reported a high degree of internal consistency (.93) for the SEC and found that the base rate for control subjects $(M=4.9, S D$ $=4.8$ ) was significantly lower than the typical rate endorsed by individuals with post-concussion syndrome $(M=13.8, S D=8.3)$.

Self-awareness. The Awareness Questionnaire (AQ; Sherer, Bergloff, Boake, High, Jr., \& Levin, 1998) is a standardised measure of self-awareness and consists of 17 items comparing an individual's abilities before and after their injury. These comparisons are rated on a 5-point scale ranging from 1 (much worse) to 5 (much better), which yields a total score ranging from 17 to 85 whereby lower scores reflect a greater degree of perceived post-injury impairments. The individual and a family member completed the respective versions of the AQ in this study. Level of awareness is represented by the AQ discrepancy score, which is calculated from the difference in scores between the ratings of the individual and significant other. Positive discrepancy scores indicate that individuals are underreporting their impairments, while negative scores suggest overreporting of impairments based upon significant others' ratings of their ability.

Depressive symptoms. The Hospital Anxiety and Depression Scale (HADS; Snaith \& Zigmond, 1994) is a standardised questionnaire with 14 items that are rated on a 4-point scale (0-3) to reflect how an individual has been feeling in the past week on a range of symptoms related to depression and anxiety. The anxiety subscale and depression subscale were derived from factor analysis and are each scored from 0 to $21(0-7=$ normal, $8-10=$ mild, 11-14 = moderate, $15-21=$ severe $)$. The HADS was selected to measure mood symptoms in the present study because the scale has sound psychometric properties (Snaith \& Zigmond, 1994) and 
contains relatively few items that overlap with common TBI symptoms (Babin, 2003).

Causal attribution. Attribution of causality or blame was assessed using the rating scale developed by Williams et al. (2002). Participants were asked to rate the extent to which the event that caused their injury was attributable to them or others using a rating scale ranging from -5 ( $m y$ own fault), to 0 (no-one's fault), to +5 (somebody else's fault).

Measures of executive function. A range of standardised measures of executive function was administered to compare the cognitive functioning of claimants and non-claimants. The measures were selected according to Lezak's (1995) classification of executive function. The Health and Safety subtest of the Independent Living Scales (ILS; Loeb, 1996) examines basic reasoning and applied problem-solving skills (Loeb, 1996). The Five-Point Test and FAS Test (see Spreen \& Strauss, 1998) are measures of fluency that assess the ability to generate and vary responses and selfmonitor for errors. The Key Search Test is a subtest of the Behavioural Assessment of the Dysexecutive Syndrome (BADS; Wilson, Alderman, Burgess, Emslie, \& Evans, 1996) that measures the ability to develop an effective plan and monitor performance while carrying out the plan. The Tinker Toy Test (TTT; Lezak, 1995) measures purposive behaviour, or the self-regulation of intentional acts or complex plans.

\section{Procedure}

The assessment session was conducted in a room in an outpatient rehabilitation unit or a community rehabilitation service. Relatives completed the AQ in a separate room or returned the questionnaire in the mail.

\section{Data Analysis}

Data screening was conducted in accordance with recommendations by Tabachnick and Fidell (2001). There were no outliers or significant violations of normality or multicollinearity. There were missing data for two relatives on the Awareness Questionnaire, thus resulting in a sample size of 52 for the relevant analyses. Between-group differences on the demographic, injury, and cognitive variables were examined using the independent $t$ test or chi-square test, according to the type of data. Additionally, group differences on measures of symptom reporting, self-awareness, mood symptoms, and causal attribution were examined using independent $t$ tests.
Due to the large number of between-group comparisons for this analysis the alpha level was set at .01 (Keppel, 1991). The association between level of symptom reporting and other variables was investigated using the Pearson product moment correlation $(r)$. In an exploratory analysis, a hierarchical multiple regression was employed to examine the hypothesis that self-awareness, mood symptoms, and causal attribution would be significantly associated with symptom reporting after controlling for compensation status.

\section{Results}

\section{Between-Group Comparisons}

The descriptive data and results of statistical comparisons between the claimant and non-claimant groups on demographic, injury, and cognitive variables are presented in Table 1. As shown, the groups were relatively well matched on demographic and cognitive variables. There was a higher proportion of individuals with mild to moderate TBI in the claimant group (41\%) as compared to the non-claimant group (22\%), although this difference was not statistically significant.

As displayed in Table 1, a comparison between the groups on the main variables identified that compared to non-claimants, claimants were more likely to report a higher level of symptoms (SEC) and greater post-injury changes in function (AQ self-ratings), and to blame others for the event that caused their injury. There was a nonsignificant trend for claimants to report a higher level of mood symptoms $(p=.039)$ and for their relatives to report a higher degree of postinjury changes on the AQ $(p=.018)$ as compared to non-claimants. There was no significant between-group difference in level of self-awareness (AQ discrepancy score).

\section{Correlates of Symptom Reporting}

A summary of symptom reporting correlates and between-group differences for gender, injury severity, and occupational status categories is presented in Table 2. A higher level of symptom reporting was associated with mild to moderate TBI, older individuals, increased self-awareness, greater post-injury changes reported by relatives, a higher level of mood symptoms, and the tendency to blame other people. There was a nonsignificant trend for individuals with greater time since injury to report more symptoms $(p=.09)$.

Additional correlational analyses identified that there was no significant association between causal attribution and self-awareness $(r=-.16)$ or between mood symptoms and self-awareness $(r=-.07)$. 
TABLE 1

Descriptive Data and Between-Group Comparisons for TBI Claimants and Non-Claimants

Variable

TBI claimant group ( $n=27)$ TBI non-claimant group $(n=27) \quad$ Statistical comparisons

\begin{tabular}{|c|c|c|c|c|}
\hline & Mean $(S D) / N$ & Mean $(S D) / N$ & $t / \chi^{2}$ & $p$ \\
\hline Age & $34.6(11.9)$ & $33.1(11.2)$ & 0.48 & .632 \\
\hline \multicolumn{5}{|l|}{ Gender } \\
\hline Male & 20 & 22 & 0.43 & .370 \\
\hline Female & 7 & 5 & & \\
\hline Education (years) & $12.2(2.1)$ & $12.4(2.4)$ & -0.24 & .812 \\
\hline \multicolumn{5}{|l|}{ Occupational status } \\
\hline Competitive employment & 6 & 7 & 0.10 & .500 \\
\hline Not competitive & 21 & 20 & & \\
\hline Time since injury (years) & $3.4(2.7)$ & $3.3(3.2)$ & 0.09 & .933 \\
\hline Posttraumatic amnesia (days) & $33.0(53.1)$ & $43.0(40.2)$ & -0.67 & .517 \\
\hline Glasgow Coma Scale & $8.0(4.2)$ & $6.6(4.4)$ & 1.08 & .289 \\
\hline \multicolumn{5}{|l|}{ Injury severity ${ }^{a}$} \\
\hline Mild/moderate & 11 & 6 & 2.15 & .120 \\
\hline Severe & 16 & 21 & 0.78 & .500 \\
\hline \multicolumn{5}{|l|}{ Cause of TBI } \\
\hline \multicolumn{5}{|l|}{ Traffic-related (motor vehicle } \\
\hline \multicolumn{5}{|c|}{$\begin{array}{l}\text { Non-traffic-related (fall, assault, } \\
\text { horse riding, home/sport/ }\end{array}$} \\
\hline \multicolumn{5}{|l|}{ Executive measures } \\
\hline Health and safety & $34.3(3.0)$ & $34.2(3.2)$ & 0.18 & .861 \\
\hline \multicolumn{5}{|l|}{ Five-Point Test } \\
\hline Designs & $22.7(8.2)$ & $25.2(8.6)$ & -1.11 & .274 \\
\hline Errors & $1.8(2.0)$ & 1.9 (1.9) & -0.21 & .837 \\
\hline \multicolumn{5}{|l|}{ FAS } \\
\hline Words & $31.6(9.3)$ & $31.4(11.1)$ & 0.07 & .947 \\
\hline Errors & $2.3(2.4)$ & $1.6(1.4)$ & 1.29 & .202 \\
\hline Key Search Test & $2.8(1.1)$ & $3.1(1.2)$ & -0.96 & .341 \\
\hline Tinker Toy Test & $7.1(1.5)$ & $7.8(1.8)$ & -1.56 & .125 \\
\hline Symptom reporting (SEC) & $16.9(7.8)$ & $10.3(7.4)$ & 3.20 & .002 \\
\hline$A Q$ discrepancy score & $2.9(8.8)$ & $6.6(9.7)$ & -1.44 & .156 \\
\hline$A Q$ self-ratings & $35.4(7.5)$ & $44.2(10.8)$ & -3.45 & .001 \\
\hline$A Q$ relative ratings & $32.3(7.4)$ & $37.7(8.3)$ & -2.44 & .018 \\
\hline Mood symptoms (HADS score) & $6.6(4.1)$ & $4.6(2.9)$ & 2.11 & .039 \\
\hline Causal attribution & $2.5(2.7)$ & $-2.2(3.3)$ & 5.63 & $<.001$ \\
\hline
\end{tabular}

Note: aclassifications of mild to moderate (GCS 9-15 or PTA $<24$ hours) and severe (GCS 3-8/15 or PTA < 24 hours) were based upon Kolb and Whishaw (1996).

$A Q=$ Awareness Questionnaire; HADS = Hospital Anxiety and Depression Scale

However, the tendency to blame others was associated with greater mood symptoms $(r=.33, p=.014)$. A significant correlation was found between selfratings and relatives' ratings on the AQ ( $r=.51$, $p<.001)$, which suggested that individuals' selfappraisal of post-injury changes was generally consistent with their relatives' perceptions.
Due to the finding that individuals with mild to moderate TBI had higher levels of symptom reporting than individuals with severe TBI, a $t$ test was conducted to examine group differences in level of self-awareness. There was a trend for individuals with severe TBI to underreport their symptoms (AQ mean discrepancy $=6.5, S D=9.6$ ) 
TABLE 2

Between-Group Differences and Correlates of Symptom Reporting (SEC)

\begin{tabular}{|c|c|c|c|c|}
\hline & \multicolumn{4}{|c|}{ Symptom reporting } \\
\hline & $M(S D)$ & $t$ test & Pearson $r$ & $p$ \\
\hline Gender & & 0.80 & - & .428 \\
\hline Males & $14.1(8.1)$ & & & \\
\hline Females & $11.9(8.6)$ & & & \\
\hline Injury severity groups & & 2.68 & - & .010 \\
\hline Mild to moderate & $17.8(7.2)$ & & & \\
\hline Severe & $11.7(8.0)$ & & & \\
\hline Post-injury occupational status & & -1.44 & & .157 \\
\hline Competitive employment & $10.77(7.9)$ & & & \\
\hline No employment & $14.49(8.2)$ & & & \\
\hline Age & - & & .32 & .019 \\
\hline Education & - & & -.05 & .740 \\
\hline Time since injury & - & & .23 & .090 \\
\hline Self-awareness ( $A Q$ discrepancy) & - & & -.47 & $<.001$ \\
\hline Relative $A Q$ score & - & & -.35 & .010 \\
\hline Mood symptoms (HADS score) & - & & .33 & .014 \\
\hline Causal attribution & - & & .41 & .002 \\
\hline
\end{tabular}

Note: $A Q=$ Awareness Questionnaire; HADS = Hospital Anxiety and Depression Scale.

to a greater extent than individuals with mild to moderate TBI (AQ mean discrepancy $=1.2, S D=$ $8.0)$, although this difference was not statistically significant $(p=.060)$.

\section{Multivariate Analysis of Symptom Reporting}

As shown in Table 1, claimants were significantly more likely to blame someone else for their injury than non-claimants $(p<.001)$. Therefore, the interactive influence of compensation status and causal attribution upon symptom reporting was initially investigated in a set of preliminary hierarchical multiple regressions. The variables of age, time since injury, and injury severity were entered together in the first step and compensation status and causal attribution were entered in the second step either separately or together. No substantial differences in the variance accounted for in level of symptom reporting was found when compensation status (Adjusted $R^{2}=.26, R^{2}$ change $=.13$, $F$ Change $=9.21, p=.004)$, causal attribution (Adjusted $R^{2}=.27, R^{2}$ change $=.14, F$ Change $=$ 9.39, $p=.004)$, or both compensation and causal attribution (Adjusted $R^{2}=.28, R^{2}$ change $=.15$, $F$ Change $=5.50, p=.007$ ) were entered in the second step. Thus, it was not possible to statistically separate the influence of compensation status and causal attribution upon level of symptom reporting. Due to the greater focus of this exploratory study on understanding the influence of compensation status and the need to maximise the participant to variable ratio, the causal attribution variable was excluded from the multivariate analysis.

A hierarchical multiple regression was conducted in which the selection and order of variables was based on logical, theoretical, and empirical grounds. In the first step, to adjust for demographic and injury-related variables, age, time since injury, and injury severity were entered (note: gender and level of education showed the least association with symptom reporting and were not included in order to maximise the participant to variable ratio). In the second step, compensation status was entered and, in the third step, mood symptoms (HADS depression) and level of self-awareness (AQ discrepancy score) were entered together. As shown in Table 3, each step accounted for a significant proportion of the variance in level of symptom reporting. Specifically, after controlling for age, time since injury, injury severity, and compensation status, mood symptoms and self-awareness significantly accounted for differences in level of symptom reporting.

\section{Discussion}

The present study investigated the associations between level of symptom reporting and compensation status, self-awareness, causal attributions, and mood symptoms following TBI. Consistent 
TABLE 3

Hierarchical Multiple Regression of Variables Associated With Symptom Reporting

\begin{tabular}{|c|c|c|c|c|c|c|c|}
\hline Variables & $R$ & $R^{2}$ (adj.) & $R^{2} \mathrm{Ch}$ & F Ch/(Beta) & $t$ & $p$ & Part $\left(s r^{2}\right)$ \\
\hline $\begin{array}{l}\text { Step 1. Age, TSI, and } \\
\text { injury severity }\end{array}$ & .43 & $.18(.13)$ & .18 & 3.58 & 一 & .020 & - \\
\hline $\begin{array}{l}\text { Step 2. Age, TSI, injury } \\
\text { severity, and } \\
\text { compensation status }\end{array}$ & .56 & $.32(.26)$ & .13 & 9.21 & 一 & .004 & - \\
\hline $\begin{array}{l}\text { Step 3. All variables } \\
\text { entered }\end{array}$ & .72 & $.52(.45)$ & .20 & 9.40 & 1.65 & $<.001$ & - \\
\hline Age & - & - & - & $(.10)$ & 0.83 & .409 & .09 \\
\hline TSI & 一 & 一 & 一 & $(.15)$ & 1.36 & .182 & .14 \\
\hline Injury severity & 一 & 一 & 一 & $(-.17)$ & -1.51 & .139 & -.16 \\
\hline Compensation status & 一 & - & - & $(-.22)$ & -1.96 & .057 & -.20 \\
\hline Mood symptoms & 一 & - & 一 & $(.35)$ & 3.21 & .002 & .33 \\
\hline Self-awareness & 一 & - & 一 & $(-.31)$ & -2.67 & .011 & -.28 \\
\hline
\end{tabular}

Note: Adj. = adjusted; $\mathrm{TSI}=$ time since injury.

with the first hypothesis and previous research, claimants reported a higher number of symptoms than non-claimants (Cartlidge, 1978; Paniak et al., 2002; McKinlay et al., 1983). Claimants were more likely to blame other people for their injury and reported greater post-injury changes, but did not display greater self-awareness than nonclaimants. Therefore, despite the lack of betweengroups differences on more objective measures of impairment (i.e., cognitive tests), the claimants reported greater impairment on subjective measures than non-claimants.

The second hypothesis was largely supported by the finding that mood symptoms and selfawareness accounted for a significant proportion of variance in level of symptom reporting after controlling for compensation status. However, the influence of causal attribution and compensation status upon level of symptom reporting was indistinguishable due to the close relation between these variables. Overall, the findings support the need for symptom reporting following TBI to be understood in a biopsychosocial framework (Brown, 2004; Kirmayer \& Taillefer, 1997).

As previously discussed, the event of TBI provides a neurological basis for a broad range of physical, cognitive, and emotional sequelae, as reflected by the range of complaints on the SEC (McKinlay et al., 1983; Mittenberg et al., 1992). However, somewhat paradoxically, in the present study individuals with mild to moderate TBI reported a higher level of symptoms than individuals with severe TBI. Consistent with previous predictions (Cicerone, 1991; Gasquoine, 1997b), the present study identified that this may have partly resulted from the individuals with severe injuries underreporting their symptoms due to reduced self-awareness. However, the difference in level of self-awareness between the severity groups cannot solely explain this finding. Therefore, it is possible that the higher symptom reporting of individuals with mild to moderate TBI was also related to the characteristics of the sample. Specifically, these participants were receiving ongoing support from outpatient or vocational rehabilitation services and may therefore be particularly symptomatic and have greater psychosocial restrictions (e.g., difficulty returning to work) than other individuals with mild to moderate TBI (Sawchyn et al., 2005). Furthermore, the present study did not examine severity or intensity of symptoms, which may be more related to severity of injury (e.g., people with severe TBI are likely to have more severe memory problems than those with mild TBI) than symptom endorsement.

In addition to examining severity of injury as a neurological basis for symptoms, relatives' ratings were used to indicate degree of post-injury changes. The number of items endorsed on the SEC and degree of self-reported post-injury changes on the AQ correlated with relatives' perception of post-injury changes on the $\mathrm{AQ}$, thus providing some support for the validity of individuals' symptoms. However, it should be noted that relatives' reports are also subject to bias from various sources, which include stress and negative emotional states, denial, personality type, and sociocultural influences, such as a generalised effect of the medico-legal system (e.g., relatives' interaction 
with health and legal professionals), and may lead to overreporting or underreporting of an individual's impairments (Gainotti, 1993; McKinlay \& Brooks, 1984). Therefore, while relatives' reports cannot be viewed as entirely reliable or objective, this collateral information supported the extent of self-reported post-injury complaints.

Overall, a main finding of this study is that level of symptom reporting was associated with mood symptoms and heightened self-awareness irrespective of compensation status. The findings are consistent with previous research concerning the association between self-reported symptoms and self-awareness (Ownsworth et al., 2002), and self-reported symptoms and emotional distress (Godfrey et al., 1993; Trahan et al., 2001). However, the present study extends upon these findings by additionally highlighting that claimants were not more accurate in their selfawareness of deficits than non-claimants and, therefore, factors other than involvement in the compensation process appear to contribute to selfappraisal of post-injury changes.

Various psychological and sociocultural mechanisms shape individuals' perceptions of health and illness. In particular, Brown (2004) argued that selffocused attention can contribute to the development and maintenance of symptoms, and is commonly associated with emotional distress. Consistent with this explanation, level of symptom reporting was associated with emotional wellbeing in the present study, although it should be noted that the mean scores on the HADS depression scale for both the claimant and non-claimant groups were not in the clinical range. Cicerone (1991) highlighted that some individuals with TBI have a tendency to overestimate their deficits, excessively monitor symptoms, and misinterpret normal variations in physical and cognitive functioning, which leads to heightened perceptions of disability. This propensity appears to be related to personality or coping style (Brown, 2004; Cicerone, 1991; Mittenberg et al., 1992).

The present study identified that claimants were more likely to blame other people for their injury than non-claimants, although it was not possible to separate the actual cause of events from causal attributions using this scale (see Williams et al., 1998). The close association between compensation status and causal attribution may be due to the claimant group being legally entitled to blame another party. Nevertheless, research suggests that the tendency to blame others appears to be associated with less effective coping (see Hart, Bogner, Whyte, \& Polansky, 2003). In the present study it was found that level of mood symptoms was associated with the tendency to blame others, while claimants did not report a significantly higher level of mood symptoms than non-claimants. It is possible that some individuals are more vulnerable to emotional distress due to their preoccupation with blame concerning the injury, or sense that their lives have been devastated due to someone else's actions. This preoccupation may interfere with the development of more adaptive coping strategies. However, this explanation needs to be investigated in prospective longitudinal research that examines the relationship between causal attribution, coping style, various aspects of emotional adjustment (i.e., anxiety, depression, and posttraumatic stress), and individuals' perceptions of their symptoms throughout the compensation process.

In addition to compensation status, verbal suggestion is a sociocultural mechanism that may contribute to symptom reporting (Brown, 2004; Mittenberg et al., 1992). In the present study, the nature of the instructions on the SEC and yes/no response format may have had a suggestive effect. The effect of suggestion upon symptom reporting could be further examined by investigating the impact of exposure to symptoms experienced by other people (e.g., attending support groups), the media (e.g., the Internet), and interaction with family and health professionals (Brown, 2004).

The limitations of the present study relate to the cross-sectional research design, sample size and characteristics, and emphasis placed upon selfreport. In relation to research design, the present study identified that different factors were associated with symptom reporting, but was unable to determine how these factors are implicated in the development and maintenance of symptoms. As previously discussed, prospective longitudinal research is required to examine the direction of this relationship. In terms of sample characteristics, a main strength of the study involved the inclusion of a group of non-claimants who were similar to the claimants in terms of demographic characteristics, injury variables, and cognitive functioning. However, there was variability in the severity of TBI within the sample, and individuals in the compensable group varied according to the type and length of compensation claim in which they were involved. Such aspects of the compensation process potentially influence symptom reporting, but were not examined due to insufficient sample size. Additionally, the sample size was relatively small given the number of variables examined in the regression analysis and, thus, the present findings should be considered exploratory. 
A further limitation of the present study is that examination of factors related to symptom reporting predominantly relied upon self-report and there was a degree of overlap in the content of these measures. As noted by Mittenberg et al. (2002), several inferential methods are recommended to examine symptom validity, which include self-report, perusal of medical records, behavioural observation, and a full neuropsychological examination incorporating psychometric tests of symptom validity or optimal effort (see Spreen \& Strauss, 1998). In this study, severity of injury from medical records and relatives' ratings of post-injury changes was examined in relation to symptom reporting, while measures of executive function were used to assess degree of cognitive impairment for the claimant and non-claimant groups. However, administering a full battery of neuropsychological tests with psychometric tests of symptom validity would have provided a detailed neuropsychological profile of each group, and may have yielded important information related to symptom reporting.

Overall, the implications of the present findings relate to the clinical interpretation of high symptom reporting and providing effective therapeutic interventions. In particular, heightened selfawareness and mood symptoms appear to be likely reasons for overreporting of symptoms, in the general absence of objective impairment. In the context of compensation, it is generally acknowledged that only a relatively small percentage of individuals consciously represent themselves as having greater impairments than they truly experience (McKinlay et al., 1983). The present findings support the view that many individuals become preoccupied with their symptoms after TBI and develop maladaptive beliefs in which they overgeneralise the effects of the injury (Cicerone, 1991). In order to provide effective treatment it is suggested that clinicians explore the aetiology of symptoms that appear out of proportion to the nature and severity of the injury (Trahan et al., 2001). There is some preliminary evidence concerning the efficacy of cognitive-behaviour therapy for modifying beliefs and alleviating symptoms after brain injury (e.g., Mittenberg, Tremont, Zielinski, Fichera, \& Rayls, 1996). However, further empirical evidence is required to support the use of different psychotherapeutic interventions, particularly in the context of compensation.

In conclusion, the present study investigated the association between symptom reporting and compensation status, self-awareness, causal attribution, and mood symptoms following TBI. As hypothesised, claimants reported a higher level of symptoms than non-claimants. However, after controlling for compensation status, level of selfawareness and mood symptoms were significantly associated with symptom reporting. The findings highlight the importance of a biopsychosocial approach to understanding high symptom reporting. Further research is recommended to investigate the development and maintenance of symptoms according to the biopsychosocial framework, and to evaluate the efficacy of psychotherapeutic interventions.

\section{Acknowledgments}

The Motor Accident Insurance Commission and School of Health and Rehabilitation Sciences Research grant and a National Health and Medical Research Council Public Health Post-Doctoral Fellowship jointly funded this study. We would like to thank Dr Shelley Allen for her helpful comments and also the staff from the Commonwealth Rehabilitation Service (ABI Team), Brain Injury Association of Queensland, Princess Alexandra Hospital (BIRU), and Prince Charles Hospital. Part of this study was presented at the Annual Meeting of Australian Society for the Study of Brain Impairment (ASSBI) and the International Neuropsychological Society (July 7-10, 2004), held in Brisbane, Australia.

\section{References}

Allen, C.C., \& Ruff, R.M. (1990). Self-rating versus neurophysiological performance of moderate versus severe head-injured patients. Brain Injury, 4, 7-17.

Babin, P.R. (2003). Diagnosing depression in persons with brain injuries: A look at theories, the DSM-IV and depression measures. Brain Injury, 17, 889-900.

Binder, L.M., \& Rohling, M.L. (1996). Money matters: A meta-analytic review of the effects of financial incentives on recovery after closed-head injury. American Journal of Psychiatry, 153, 7-10.

Bogod, N.M., Mateer, C.A., \& Macdonald, S.W.S. (2003). Self-awareness after traumatic brain injury: A comparison of measures and their relationship to executive functions. Journal of the International Neuropsychological Society, 9, 450-458.

Brown, R.J. (2004). Psychological mechanisms of medically unexplained symptoms: An integrative conceptual model. Psychological Bulletin, 5, 793-812.

Burgess, P.W., Alderman, N., Evans, J.J., Emslie, H., \& Wilson, B.A. (1998). The ecological validity of tests of executive function. Journal of the International Neuropsychological Society, 4, 547-558.

Cartlidge, N.E.F. (1978). Post-concussional syndrome. Scottish Medical Journal, 23, 103. 
Cicerone, K. (1991). Psychotherapy after mild traumatic brain injury: Relation to the nature and severity of subjective complaints. Journal of Head Trauma Rehabilitation, 6, 30-43.

Gainotti, G. (1993). Emotional and psychosocial problems after brain injury. Neuropsychological Rehabilitation, 3, 259-277.

Gasquoine, P.G. (1997a). Emotional, cognitive, and motivational deficits in compensation-seeking, suspected brain injury cases. Applied Neuropsychology, 99-106.

Gasquoine, P.G. (1997b). Postconcussion symptoms. Neuropsychology Review, 7, 77-85.

Godfrey, H.P.D., Partridge, F.M., Knight, R.G., \& Bishara, S. (1993). Course of insight disorder and emotional dysfunction following closed head injury: A controlled cross-sectional follow-up study. Journal of Clinical and Experimental Neuropsychology, 15, 503-515.

Hart, T., Bogner, J.A., Whyte, J., \& Polansky, M. (2003). Attribution of blame in accidental and violencerelated traumatic brain injury. Rehabilitation Psychology, 48, 86-92.

Jorge, R.E., Robinson, R.G., \& Arndt, S.V. (1993). Are there symptoms that are specific for depressed mood in patients with traumatic brain injury? Journal of Nervous and Mental Disease, 181, 91-99.

Karszmark, P., Hall, K., \& Englander, J. (1995). Lateonset post-concussion symptoms after mild brain injury: The role of premorbid, injury-related, environmental, and personality factors. Brain Injury, 9, 21-26.

Keppel, G. (1991). Design and analysis. Englewood Cliffs, NJ: Prentice-Hall.

Kirmayer, L.J., \& Taillefer, S. (1997). Somatoform disorders. In S.M. Turner \& M. Hersen (Eds.), Adult psychopathology and diagnosis (3rd ed., pp. 333-383). New York: Wiley.

Kolb, B., \& Whishaw, I.Q. (1996). Fundamentals of human neuropsychology (4th ed.). New York: W.H. Freeman.

Kreutzer, J.S., Harris-Marwitz, J., \& Myers, S.L. (1990). Neuropsychological issues in litigation following traumatic brain injury. Neuropsychology, 4, 249-259.

Lezak, M.D. (1995). Neuropsychological assessment (3rd ed.). New York: Oxford University Press.

Loeb, P.A. (1996). The Independent Living Scales manual. San Antonio, TX: The Psychological Corporation.

McKinlay, W.W., \& Brooks, D.N. (1984). Methodological problems in assessing psychosocial recovery following severe head injury. Journal of Clinical and Experimental Neuropsychology, 6, 87-99.

McKinlay, W.W., Brooks, D.N., \& Bond, M.R. (1983). Post-concussional symptoms, financial compensation and outcome of severe head injury. Journal of
Neurology, Neurosurgery and Psychiatry, 46, 1084-1091.

Mittenberg, W., DiGiulio, D.V., Perrin, S., \& Bass, A.E. (1992). Symptoms following mild head injury: Expectation as aetiology. Journal of Neurology, Neurosurgery, and Psychiatry, 55, 200-204.

Mittenberg, W., Patton, C., Canyock, E.M., \& Condit, D.C. (2002). Base rates of malingering and symptom exaggeration. Journal of Clinical and Experimental Neuropsychology, 24, 1094-1102.

Mittenberg, W., Tremont, G., Zielinski, R.E., Fichera, S., \& Rayls, K.R. (1996). Cognitive-behavioural prevention of postconcussion syndrome. Archives of Clinical Neuropsychology, 11, 139-145.

Ownsworth, T.L., McFarland, K., \& Young, R. McD. (2002). The investigation of factors underlying deficits in self-awareness and self-regulation. Brain Injury, 16, 291-309.

Ownsworth, T.L., \& Oei, T.P.S. (1998). Depression after traumatic brain injury: Conceptualisation and treatment considerations. Brain Injury, 12, 735-751.

Paniak, C., Reynolds, S., Toller-Lobe, G., Melnyk, A., Nagy, J., \& Schmidt, D. (2002). A longitudinal study of the relationship between financial compensation and symptoms after treated mild traumatic brain injury. Journal of Clinical and Experimental Neuropsychology, 24, 187-193.

Sawchyn, J.M., Mateer, C.A., \& Suffield, J.B. (2005). Awareness, emotional adjustment, and injury severity in postacute brain injury. Journal of Head Trauma Rehabilitation, 20, 301-314.

Sherer, M., Bergloff, P., Boake, C., High, W., Jr., \& Levin, E. (1998). The awareness questionnaire: Factor structure and internal consistency. Brain Injury, 12, 63-68.

Snaith, R.P., \& Zigmond, A.S. (1994). The Hospital Anxiety and Depression Scale manual Windsor, Berkshire, UK: NFER-NELSON.

Spreen, O., \& Strauss, E. (1998). A compendium of neuropsychological tests (2nd ed). Oxford, UK: Oxford University Press.

Suhr, J.A., \& Gunstad, J. (2002). Postconcussive symptom report: The relative influence of head injury and depression. Journal of Clinical and Experimental Neuropsychology, 24, 981-993.

Tabachnick, B.G., \& Fidell, L.S. (2001). Using multivariate statistics (4th ed). Boston, MA: Allyn \& Bacon.

Trahan, D.E., Ross, C.E., \& Trahan, S.L. (2001). Relationship among postconcussional-type symptoms, depression, and anxiety in neurologically normal young adults and victims of mild brain injury. Archives of Clinical Neuropsychology, 16, 435-445.

Williams, A.D. (1997). Special issues in the evaluation of mild traumatic brain injury. In R.J. McCaffrey (Ed.), The practice of forensic neuropsychology (pp. 71-89). New York: Plenum Press.

Williams, W.H., Evans, J.J., Needham, P., \& Wilson, B.A. (2002). Neurological, cognitive and attribu- 
tional predictors of posttraumatic stress symptoms after traumatic brain injury. Journal of Traumatic Stress, 15, 397-400.

Williams, W.H., Williams, J.M.G., \& Ghadiali, E.J. (1998). Autobiographical memory in traumatic brain injury: Neuropsychological and mood predictors of recall. Neuropsychological Rehabilitation, 8 , 43-60.
Wilson, B.A., Alderman, N., Burgess, P., Emslie, H., \& Evans, J.J. (1996). Behavioural assessment of the dysexecutive syndrome. Bury St Edmunds, UK: Thames Valley Test Company.

Youngjohn, J.R., Burrows, L., \& Erdal, K. (1995). Brain damage or compensation neurosis? The controversial post-concussion syndrome. The Clinical Neuropsychologist, 9, 112-123. 